\title{
Cytotoxicity and effect of extraction methods on the chemical composition of essential oils of Moringa oleifera seeds
}

\author{
Rowland Monday Ojo KAYODE, Anthony Jide AFOLAYAN \\ (Medicinal Plant and Economic Development Research Centre, Department of Botany, \\ University of Fort Hare, Private Bag X1314, Alice 5700, South Africa) \\ E-mail: kayodermosnr@gmail.com; AAfolayan@ufh.ac.za \\ Received Nov. 11, 2014; Revision accepted Apr. 30, 2015; Crosschecked July 8, 2015
}

\begin{abstract}
Renewed interest in natural materials as food flavors and preservatives has led to the search for suitable essential oils. Moringa oleifera seed essential oil was extracted by solvent-free microwave and hydrodistillation. This study assessed its chemical constituents. Cytotoxicity of the oils was investigated using hatchability and lethality tests on brine shrimps. A total of 16 and 26 compounds were isolated from the hydrodistillation extraction (HDE) and solvent-free microwave extraction (SME) oils, respectively, which accounted for $97.515 \%$ and $97.816 \%$ of total identifiable constituents, respectively. At $24 \mathrm{~h}$ when the most eggs had hatched, values of the SME (56.7\%) and HDE $(60.0 \%)$ oils were significantly different $(P<0.05)$ from those of sea water $(63.3 \%)$ and chloramphenicol $(15.0 \%)$. Larva lethality was different significantly $(P<0.05)$ between HDE and SME oils at different concentrations and incubation periods. The median lethal concentration ( $L C_{50}$ ) of the oils was $>1000 \mathrm{mg} / \mathrm{ml}$ recommended as an index for non-toxicity, which gives the oil advantage over some antioxidant, antimicrobial, therapeutic, and preservative chemicals.
\end{abstract}

Key words: Moringa oleifera seed, Extraction methods, Essential oil, Cytotoxicity doi: 10.1631 jzus.B1400303

Document code: A

CLC number: Q946

\section{Introduction}

Moringa oleifera Lamarch is one of the most widely distributed and naturalized species of the monogeneric family Moringaceae (Ramachandran et al., 1980). The plant is known for its nutritional and medicinal value. It contains some phytochemicals, which make it a good source of antioxidant and antimicrobial substances. The leaves, pod, and seed are now being used as a food commodity in some tropical countries where protein malnutrition exists. Moringa leaves are reported to be a rich source of $\beta$-carotene, protein, vitamin $\mathrm{C}$, calcium, and potassium, which makes it a good source of natural antioxidants and thus may enhance the shelf-life of fat-containing

\footnotetext{
¿Corresponding author

(DD ORCID: Rowland Monday Ojo KAYODE, http://orcid.org/00000002-2828-2519

(c) Zhejiang University and Springer-Verlag Berlin Heidelberg 2015
}

foods due to the presence of various types of antioxidant compounds such as ascorbic acids, flavonoids, phenolics, and carotenoids (Dillard and German, 2000; Siddhuraju and Becker, 2003). The ethanolic extract of the seed has shown the presence of some bioactive compounds such as benzyl carbamate, benzyl isothiocyanate, niazimicin, sitosterol, and niazirin (Guevara et al., 1999). In recent times, there has been growing interest in Moringa plant propagation for industrial application in developing countries like Nigeria.

Essential oils are aromatic and volatile compounds found in most parts of plant materials such as the leaves, seed, flower, bark, fruit, and peel (Sánchez et al., 2010). The chemical compositions of essential oils are secondary metabolites, which play important roles in a plant's defense against microbial attacks and have been added to foods as spices for decades (Hyldgaard et al., 2012). The active compounds in essential oils have been broadly divided into four 
groups according to their chemical structures. The first group is terpenes such as limonene, $p$-cymene, sabinene, terpinene, and pinene. Terpenes are hydrocarbons produced from a combination of several isoprene units $\left(\mathrm{C}_{5} \mathrm{H}_{8}\right)$, and are synthesized in the cytoplasm of plant cells; they have a hydrocarbon backbone, which can be rearranged into cyclic structures by cyclases, thus forming monocyclic or bicyclic structures (Caballero et al., 2003). The main terpenes are monoterpenes $\left(\mathrm{C}_{10} \mathrm{H}_{16}\right)$ and sesquiterpenes $\left(\mathrm{C}_{15} \mathrm{H}_{24}\right)$, although other chains such as diterpenes $\left(\mathrm{C}_{20} \mathrm{H}_{32}\right)$, triterpenes $\left(\mathrm{C}_{30} \mathrm{H}_{40}\right)$, and even longer chains exist (Hyldgaard et al., 2012). The second group is terpenoids such as thymol, citronellal, piperitone, carvacrol, linalyl acetate, and menthol. Terpenoids are terpenes that undergo biochemical modification via enzymes that incorporate oxygen molecules and shift or remove methyl groups (Caballero et al., 2003). According to Caballero et al. (2003) and Hyldgaard et al. (2012), terpenoids are subdivided into alcohols, aldehydes, ketones, esters, ethers, epoxides, and phenols. The third group is phenylpropenes, which constitute a subfamily among the various groups of organic compounds called phenylpropanoids that are synthesized from the amino acid precursor phenylalanines in plants. Phenylpropanoids have their names from the six-carbon aromatic phenol group and the three-carbon propene tail of cinnamic acid, produced in the first step of phenylpropanoid biosynthesis (Hyldgaard et al., 2012). In addition, there are essential oils, which contain a number of different degradation products originating from unsaturated fatty acids, lactones, terpenes, glycosides, and compounds that contain either sulfur or nitrogen (Caballero et al., 2003; Hyldgaard et al., 2012). The chemical composition of a specific essential oil may vary depending on the season of harvest and the methods used to extract the oil (Pereira and Meireles, 2010; Sánchez et al., 2010; Demuner et al., 2011; Hyldgaard et al., 2012). Essential oils from plant sources have been isolated by traditional distillation using water, steam, water and steam, organic solvents such as alcohol, ether, hexane, or their mixtures at different concentrations. Essential oils have also been isolated by hydrodistillation (Khajeh et al., 2004; Okoh and Afolayan, 2011) and supercritical carbon dioxide extraction (Khajeh et al., 2004). Steam and solvent distillation has resulted in degradation and loss of several volatile compounds in addition to the formation of new compounds due to the prolonged extraction period (Okoh and Afolayan, 2011). The degradation of unsaturated components of oils through thermal and/or hydrolytic processes is a disadvantage of these methods (Khajeh et al., 2004). Brenes and Roura (2010) reported the use of essential oil as a good antioxidant substance in diets. Scientist's keen interest in essential oils and their application in food preservation have been geared in recent years by the continuous increase of negative consumer perception of most synthetic preservatives (Hyldgaard et al., 2012).

Presently, about 3000 kinds of essential oils have been identified, out of which only 300 are being commercially used in the flavor and fragrance market (Burt, 2004). The food industry primarily uses essential oils as aroma and color substances in food and as such, detailed knowledge of their chemical properties, which may give information on their effect on food matrix components, is important. Hence, this work is designed to assess the cytotoxicity potentials and effect of extraction methods on the chemical constituents of the essential oil of Moringa oleifera seeds. Knowledge gained from the study may provide information on a suitable method of extraction of the essential oil for industrial application, and may facilitate implementation of the essential oil as a natural source of plant and animal food additives.

\section{Materials and methods}

\subsection{Sources and preparation of Moringa oleifera seeds}

The seeds $(1 \mathrm{~kg})$ of matured Moringa oleifera plant were collected in clean polythene bags at the University of Ilorin Moringa Plantation Farm, Ilorin, Kwara State, Nigeria. The seeds were taken to the Department of Plant Biology, Faculty of Science, University of Ilorin, Ilorin, Kwara State, Nigeria for authentication. The Moringa seeds were carefully crushed using a pestle and mortar to de-hull the seeds. Thereafter, the seeds were manually cleaned by separation from the hulls. The cleaned seeds were packaged into a clean and ice-packed plastic container before transporting to the Medicinal Plant and Economic Research Centre, University of Fort Hare, Republic of South Africa for further analysis. 


\subsection{Solvent-free microwave extraction (SME) of the essential oil of Moringa oleifera seeds}

Two hundred grams of uncoated Moringa seeds were weighed into the reactor of an automatic millstone Dry DIST microwave apparatus. The multimode microwave reactor has a twin magnetron $(2800 \mathrm{~W}$, $2450 \mathrm{MHz}$ ) with a maximum delivered power of $1000 \mathrm{~W}$ in $10 \mathrm{~W}$ increments. A rotating microwave diffuser ensures homogenous microwave distribution throughout the plasma-coated polytetrafluoroethylene (PTFE) cavity $(35 \mathrm{~cm} \times 35 \mathrm{~cm} \times 35 \mathrm{~cm})$. The temperature was monitored by a shielded thermocouple (ATC-300) inserted directly into the corresponding container. Temperature was controlled by a feedback to the microwave power regulator, which indicated that the initial temperature was $20^{\circ} \mathrm{C}$ and increased at $7.5^{\circ} \mathrm{C} / \mathrm{min}$ up to $100{ }^{\circ} \mathrm{C}$ before commencement of essential oil extraction for $10 \mathrm{~min}$. After complete extraction of the oil, the temperature decreased at $7.0^{\circ} \mathrm{C} / \mathrm{min}$ until $30^{\circ} \mathrm{C}$ was reached. The total running time of the extraction process was $30 \mathrm{~min}$. The extracted essential oil was retained in $1.0 \mathrm{ml} n$-hexane used as solvent phase in the oil collector column of the equipment. Afterwards, the essential oil was carefully separated into a glass sample vial and kept in the refrigerator at $4{ }^{\circ} \mathrm{C}$ for further analysis.

\subsection{Hydrodistillation extraction (HDE) of the es- sential oil of Moringa oleifera seeds}

Two hundred grams of uncoated Moringa seeds were weighed into a 5-L capacity of a glass HDE apparatus containing $3.0 \mathrm{~L}$ of sterile distilled water. The extracted essential oil was retained in $1.0 \mathrm{ml}$ $n$-hexane used as solvent phase in the oil collector column of the hydrodistillation apparatus. Thereafter, the essential oil was carefully separated into a glass sample vial and kept in the refrigerator at $4{ }^{\circ} \mathrm{C}$ for chemical analysis. The essential oil yield was calculated using the formula below: oil yield $(\%)=($ weight of oil extracts)/(weight of sample) $\times 100 \%$.

\subsection{Determination of chemical composition of the essential oil of Moringa oleifera seeds}

The seed oil of Moringa oleifera was analyzed with an Agilent 6890N Network gas chromatographic (GC) system connected to an Agilent 5973 Network mass selective detector. The machine was equipped with a mass spectroscopy (HP-5MS) column (30 m×
$0.25 \mathrm{~mm} 5 \%$ phenyl methylpolysiloxane capillary column, film thickness $(0.25 \mu \mathrm{m})$; injector temperature $250{ }^{\circ} \mathrm{C}$ and transfer line temperature $240{ }^{\circ} \mathrm{C}$ ). The oven temperature was programmed as follows: initial temperature was $50{ }^{\circ} \mathrm{C}$ for $15 \mathrm{~min}$, and then increased at $2{ }^{\circ} \mathrm{C} / \mathrm{min}$ up to $150{ }^{\circ} \mathrm{C}$, which was maintained for $10 \mathrm{~min}$ before a further increase at $2{ }^{\circ} \mathrm{C} / \mathrm{min}$ up to $220{ }^{\circ} \mathrm{C}$ which was maintained for $20 \mathrm{~min}$ (total run time is $130 \mathrm{~min}$ ). Hydrogen was used as the carrier gas at $2 \mathrm{ml} / \mathrm{min}$. The amount of sample injected into the machine was $5 \mu$ l (split ratio 1:20), while ionization energy was $70 \mathrm{eV}$. Qualitative identification of the different constituents was performed by comparison of their relative retention time (RT) and mass spectra with those of standard reference compounds or by comparison of their retention indices and mass spectra with those shown in the literature (Adams, 1995). Probability merge search software and the NIST MS spectra search program were used. The relative amount (RA) of an individual component of the essential oil was expressed as a percentage of the peak area relative to the total peak area. The method of Kováts (1958) modified by IUPAC (1997) was adopted in the calculation of Kováts indices (KI) of the components relative to the $\mathrm{RT}$ of a series of $n$-alkanes with linear interpolation on the HP-5MS column.

\subsection{Hatchability test of brine shrimps}

This was carried out to assess the effect of Moringa oleifera essential oil extracted by different methods on the hatchability of brine shrimp eggs. Twenty shrimp eggs were introduced into a 40-ml capacity sterile petri-dish each containing freshly prepared mixture of the essential oil and sea water at different concentration gradients of $250,500,750$, $1000,1500,2000,4000$, and $6000 \mu \mathrm{g} / \mathrm{ml}$. A control sample consisting of $0.1 \%$ dimethyl sulphoxide (DMSO; $0.1 \mathrm{ml}$ DMSO in $100 \mathrm{ml}$ sea water) without the addition of oil was prepared. Each treatment and control sample was distributed in triplicate into the sterile petri-dish before incubation at $28{ }^{\circ} \mathrm{C}$ under constant illumination in a digital incubator (MRC Laboratory Equipment, Model LE-509). Thereafter, the petri-dishes were examined with the aid of a hand lens against a white background that allows the moving larvae (naupili) to be separated from shells and counted at every $12 \mathrm{~h}$ for $72 \mathrm{~h}$. The percentage 
hatchability was calculated by comparing the number of hatched naupili with the total number of brine shrimp eggs stocked (Carballo et al., 2002).

\subsection{Toxicity test on brine shrimps}

This was performed in order to predict the toxicity level of the essential oil of Moringa oleifera seeds extracted by different methods. The test was conducted according to the methods of Okoh and Afolayan (2011) and Nkya et al. (2014). The brine shrimp eggs were sourced from Ocean Star International, Inc. (USA) by the Medicinal Plant and Economics Development Unit, Department of Botany, University of Fort Hare, South Africa. Shrimp eggs were placed into natural sea water in a $40-\mathrm{ml}$ capacity sterile petri-dish and incubated at $28{ }^{\circ} \mathrm{C}$ under constant illumination in a digital incubator (Model BOD-150) for $48 \mathrm{~h}$ to hatch. The hatched shrimps (naupili) in the petri-dishes were attracted with a light source to one side and then harvested. Stock solution of the oil containing $100 \mathrm{mg} / \mathrm{ml}$ DMSO was prepared by dissolving $100 \mathrm{mg}$ of the essential oil in $1.0 \mathrm{ml}$ of DMSO. From the stock solution, $100 \mathrm{ml}$ of different concentrations of 250, 500, 750, 1000, 1500, 2000, 4000 , and $6000 \mu \mathrm{g} / \mathrm{ml}$ of the essential oils in natural sea water were prepared. A control sample without essential oil consisting of $0.1 \%$ DMSO in sea water was prepared. The control and each of the treatment samples were distributed in triplicate petri-dishes. Thereafter, 15 harvested brine shrimp larvae were added to each of the petri-dishes before incubation at $28{ }^{\circ} \mathrm{C}$ in a digital incubator (MRC Laboratory Equipment, Model LE-509). The petri-dishes were examined with the aid of a lens against a white background for mortality at every $12 \mathrm{~h}$ for $72 \mathrm{~h}$.

To ensure that larvae (naupili) mortality is attributed to the bioactive compounds inherent in the oil and not as a result of starvation or contacts with DMSO, the number of dead larvae in the control was compared with the number of dead larvae in each of the treatment samples. The percentage of larva mortality (LM) was calculated according to this formula: LM $(\%)=\left[\left(N-N_{\mathrm{T}}\right)-\left(N-N_{\mathrm{C}}\right)\right] / N \times 100 \%$, where $N$ is the number of larvae used and constant for treatments and control, $N_{\mathrm{T}}$ is the number of survived larvae in each treatment, and $N_{\mathrm{C}}$ is the number of survived larvae in the control.

\subsection{Design and statistical analysis}

Completely randomized design was used in the experiment. Data obtained for mortality in every treatment and positive control were used to construct a dose against response graph. The best-fit line from the linear regression analysis of the percentage mortality versus concentration was used to determine median lethal concentration $\left(\mathrm{LC}_{50}\right)$ values. Treatments having values of $\mathrm{LC}_{50}$ greater than $1000 \mu \mathrm{g} / \mathrm{ml}$ were considered nontoxic (Gupta et al., 1996). The analysis was performed on MINITAB Version 12 for Windows. One-way analysis of variance followed by Fisher's least significant difference post-hoc analysis was used to test for the effect of concentration and time of exposure of the essential oil.

\section{Results}

\subsection{Chemical composition of the essential oil}

The yield, retention indices, and chemical constituents of the essential oil of Moringa oleifera seeds processed by different methods are indicated in Table 1. The yields of a faint yellow-colored volatile oil of the SME and HDE processes were 6.694 and $6.982 \mathrm{~g} / \mathrm{kg}$, respectively. From the GC-MS analysis, a total of 16 and 26 chemical compounds were isolated from the HDE and SME volatile oils, which accounted for $97.515 \%$ and $97.816 \%$ of the total identifiable constituents, respectively. According to Chuang et al. (2007), GC-MS analysis has revealed 44 different chemical compounds in Moringa oleifera leaf extracts. Cyclopentane (51.493\%) was the predominant compound in the oil processed by SME, followed by $n$-hexadecanoic acid $(11.143 \%), 2-(E)$-decenal $(4.369 \%)$, eicosane $(3.102 \%)$, and 1,5-dimethyl-2pyrrolecarbonitrile (2.003\%). Other compounds ranged between $0.122 \%$ (tetracosane) and $1.924 \%$ (1-nonanol). The oil extracted by HDE showed the presence of tetracosane $(34.259 \%)$ as the most abundant compound, followed by heptadecane $(22.202 \%)$, eicosane (19.583\%), $n$-hexadecanoic acid $(8.454 \%)$, phenanthrenecarboxylic acid $(3.784 \%)$, and cyclopentane $(3.598 \%)$, while other compounds ranged between $0.215 \%$ (phthalic acid) and $1.718 \%$ (acetamide). The oxygenated compounds of the SME and HDE processed oils indicated $27.678 \%$ and $15.979 \%$, while 
Table 1 Chemical compounds of the essential oil of Moringa oleifera seeds extracted using solvent-free microwave and hydrodistillation methods

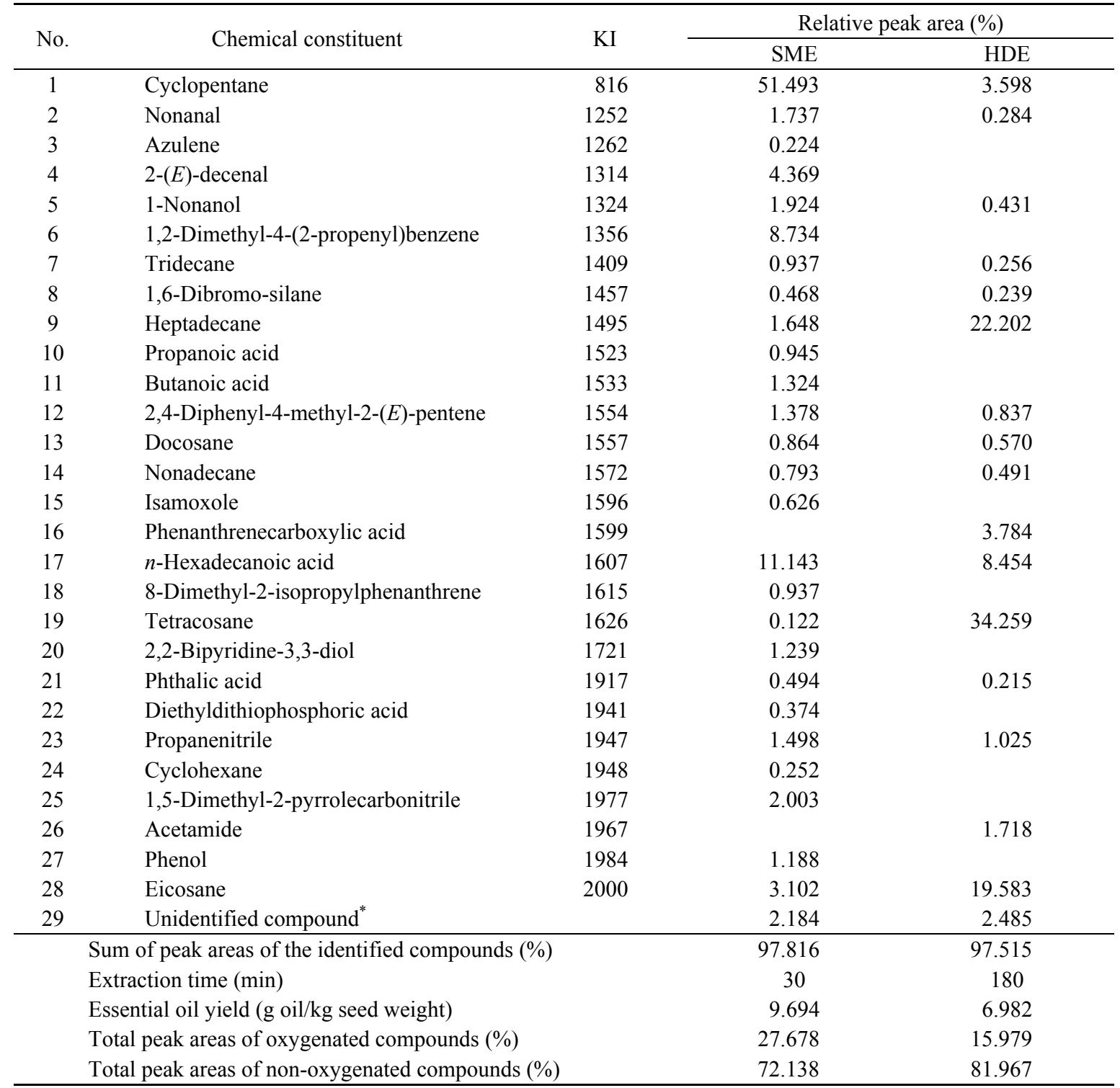

KI: Kováts index; SME: solvent-free microwave extraction; HDE: hydrodistillation extraction. ${ }^{*}$ No matches found in the $\mathrm{C}:$ Database $\backslash$ NIST05; DB-5MS non-polar column relative to $\mathrm{C}_{3}$ to $\mathrm{C}_{24} n$-alkanes

the non-oxygenated compounds showed $72.138 \%$ and $81.967 \%$, respectively.

Fourteen chemical isolates consisting of 8 oxygenated and 6 non-oxygenated compounds were concurrently detected in both the HDE and SME volatile oil samples as presented in Table 1 .

\subsection{Effect of the oil on hatchability of brine shrimp eggs}

Fig. 1 shows the percentage hatchability of brine shrimp eggs at different incubation periods in the volatile oil. At the end of $12 \mathrm{~h}$, not less than $1.7 \%$ and $3.3 \%$ of the eggs incubated in the SME and HDE oil treated samples were hatched and rapidly increased to maximum values of $66.7 \%$ and $68.3 \%$, respectively, in $48 \mathrm{~h}$. The values obtained in the SME (56.7\%) and HDE $(60.0 \%)$ oil-treated samples were significantly different $(P<0.05)$ compared with the chloramphenicoltreated sample $(15.0 \%)$ and the natural sea water $(63.3 \%)$ at $24 \mathrm{~h}$ when the most eggs hatched. Fig. 2 presents the percentage hatchability of the brine shrimp eggs at different concentrations of the essential oil. 
Hatchability was significantly different $(P<0.05)$ among oil-treated samples, sea water, and positive control at all levels. The value recorded in the chloramphenicoltreated sample was significantly lower $(P<0.05)$ at all treatment levels compared with the oil-treated samples and sea water.

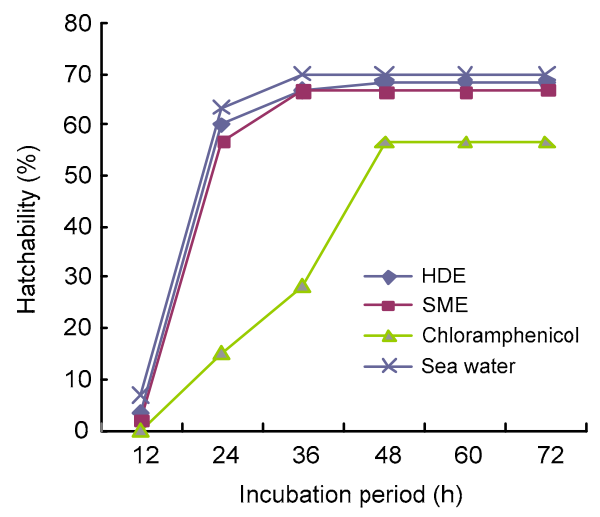

Fig. 1 Hatchability success of brine shrimp eggs at different periods of incubation in the essential oil of Moringa oleifera seeds extracted by different methods

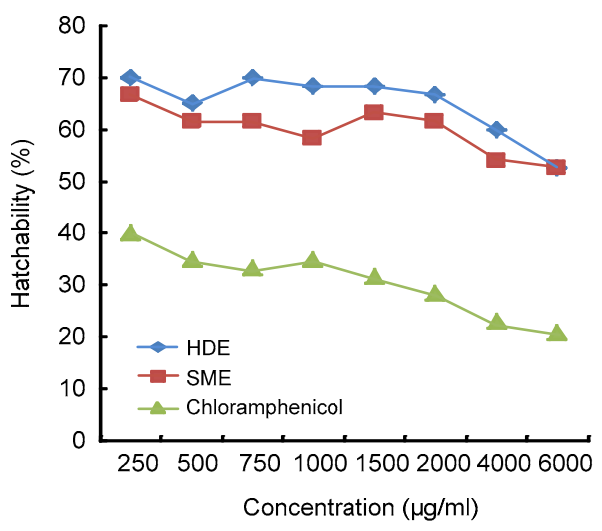

Fig. 2 Hatchability of brine shrimp eggs incubated in different concentrations of the essential oil of Moringa oleifera seeds extracted by different methods

\subsection{Effect of the oil on lethality of brine shrimp larvae}

The mortality of brine shrimp larvae incubated in different concentrations of the essential oil of Moringa oleifera seeds is presented in Fig. 3. The values obtained for mortality of the brine shrimp larvae were significantly higher $(P<0.05)$ at all levels in the chloramphenicol-treated sample compared with essential oil-treated samples. Mortality of the brine shrimp larvae at different periods of incubation in the essential oil extracted by different methods is illustrated in Fig. 4. Naupili mortality was first observed after $24 \mathrm{~h}$ in the chloramphenicol-treated sample and was in acute status from 24 to $36 \mathrm{~h}$ when it became completely logarithmic after $48 \mathrm{~h}$ in all the samples except natural sea water. The shrimp mortality was significantly different $(P<0.05)$ in the HDE and SME oils at $48 \mathrm{~h}$ until experiment was terminated. The value recorded at every period of assessment was significantly lower $(P<0.05)$ in the sea water compared to the positive control and the essential oiltreated samples. This study revealed $\mathrm{LC}_{50}$ of the $\mathrm{SME}$ and HDE oils at 2906.83 and $3495.82 \mu \mathrm{g} / \mathrm{ml}$, respectively, as presented in Table 2 . These values were greater than $2716.71 \mu \mathrm{g} / \mathrm{ml}$ recorded for chloramphenicol used as a positive control.

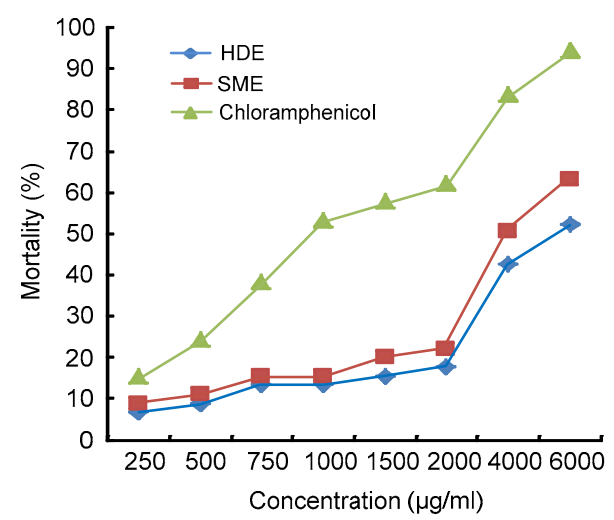

Fig. 3 Mortality of brine shrimp larvae incubated in different concentrations of the essential oil of Moringa oleifera seeds extracted by different methods

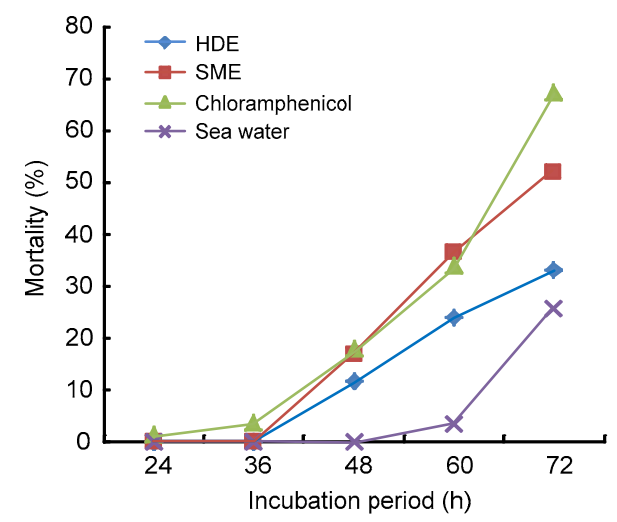

Fig. 4 Mortality of brine shrimp larvae at different periods of incubation in the essential oil Moringa oleifera seeds extracted by different methods 
Table 2 Mortality of brine shrimp larvae as indicated by $\mathrm{LC}_{50}$ in differently extracted Moringa oleifera seed essential oils

\begin{tabular}{ccccc}
\hline Treatment & $\mathrm{LC}_{50}(\mu \mathrm{g} / \mathrm{ml})$ & Regression equation & $R^{2}(\%)$ & $P$-value \\
\hline SME & 2906.83 & $Y=0.0172 X+0.0025$ & 97.50 & 0.000 \\
HDE & 3495.82 & $Y=0.0143 X+0.0097$ & 98.30 & 0.000 \\
Chloramphenicol & 2716.71 & $Y=0.0184 X+0.0125$ & 84.30 & 0.003 \\
\hline
\end{tabular}

SME: solvent-free microwave extraction; HDE: hydrodistillation extraction. $R^{2}$ : coefficient of determination of the regression equation; $P$-value: significance level of the regression equation, which is significant when $P<0.05$

\section{Discussion}

The pattern of occurrence of the oxygenated and non-oxygenated compound obtained in the extracted oils is in agreement with the findings of Okoh et al. (2010) who similarly reported higher value of oxygenated $(28.63 \%)$ compounds compared with the non-oxygenated $(26.98 \%)$ constituents of the essential oil of Rosmarinus officinalis extracted by solventfree microwave technique. Okoh et al. (2010) attributed this phenomenon to diminution of the thermal and hydrolytic properties of SME compared with the hydrodistillation method which required a large quantity of water for extraction. The absence of most chemical compounds in the oil extracted by the hydrodistillation process may be attributed to the water solubility potential and/or the thermal instability of the various compounds inherent in Moringa oleifera seeds. Thus, the polar property of water makes it a good solvent for the acceleration of many reactions via carbocation intermediates (Lucchesi et al., 2004). Consequently, the emergence of new compounds in the oil extracts of both techniques may be linked to the partial or complete degradation of some unsaturated components during oil extraction from the seeds Khajeh et al. (2004) earlier reported that the degradation of unsaturated fats in oil through thermal and/or hydrolytic process is disadvantage of steam and solvent extraction methods. The microwave irradiation highly accelerated the extraction process without causing considerable changes in the volatile oil composition, a phenomenon already described by Pare and Belanger (1997) and Okoh et al. (2010).

The presence of $n$-hexadecanoic acid (palmitic acid) in the oils collected by both processing methods is in agreement with the suggestions of Lyman et al. (1990) that hydrolysis should not be an important factor that may influence the fate of the compound during processing, since it lacks functional groups that could hydrolyze under environmental conditions. Meylan and Howard (1993) reported that palmitic acid exhibited negligible direct photo-degradation in sea water. Palmitic acid is one of the more common fatty acids found in natural fats and oils (Verschueren, 1996), and has been detected in matured grains of brown rice and in the natural constituents of many plants (Taira et al., 1988). Fatty acids are an important part of the normal daily diet of mammals, birds, and invertebrates (Anneken et al., 2006).

Cyclopentane, which appeared to be the most abundant compound in the SME volatile oil, was detected in the smaller quantity of $3.598 \%$ in the essential oil extracted by the HDE method. This phenomenon is expected and also in conformity with New Jersey Department of Health and Senior Services (1999) who reported that cyclopentane had a low boiling point of $49.5^{\circ} \mathrm{C}$ and was also strongly soluble in water; perhaps the compound became unrecoverable in the condensate or merely dissolved in the still water during a prolonged hydrodistillation process of the essential oil from the seeds. From the results obtained in Fig. 2, it could be deduced that the volatile oil of Moringa oleifera seeds extracted by both HDE and SME had no potential to completely inhibit hatching of the brine shrimp eggs at the concentrations used in this study. Increased percentage mortality was noticed as the concentrations of the essential oil increased (Fig. 3). This phenomenon seems to have depended on the length of incubation period as earlier reported by some authors (Pour and Sasidharan, 2011; Otang et al., 2013). It may be suggested that the larvae had reached their instar phase and exhibited greater sensitivity to the test compound (Lewis, 1995), which led to a maximum mortality at a longer exposure time. An incubation period greater than $60 \mathrm{~h}$ had no significant changes on 
the mortality of larvae in the oil treated samples compared with the control (sea water). Similar observations were made when the naupili of brine shrimps were exposed to the methanol extracts of different parts of Lantana camara (Pour and Sasidharan, 2011) and hexane and acetone extracts of three South African plants (Otang et al., 2013).

The suspected cytotoxic chemical constituents isolated from the Moringa oleifera seed essential oils include cyclopentane, $n$-hexadecanoic acid, 2-(E)decenal, eicosane, 1,5-dimethyl-2-pyrrolecarbonitrile, 1-nonanol, tetracosane, heptadecane, phenanthrenecarboxylic acid, phthalic acid, diethyldithiophosphoric acid, and acetamide. Previous studies had elucidated the presence of $n$-hexadecanoic and phthalic acids in lemon, acetamide and propanoic acid in garlic, and 1,5-dimethyl-2-pyrrolecarbonitrile and phenol in turmeric (Nyaitondi, 2007). Diethyldithiophosphoric acid has been identified as a useful compound for the production of organophosphate insecticides such as parathion and parathion-methyl (Okuniewski and Becker, 2011). The crude methanolic plant extract containing most of the suspected chemical compounds has demonstrated antibacterial activities on both Gram-positive and Gram-negative bacteria (Nyaitondi, 2007). Polyunsaturated fatty acids are known to be essential for the maintenance of good health, but are subject to peroxidation when in contact with atmospheric oxygen leading to fragmentation and reactive decomposition. A prominent autoxidation product of either arachidonic acid or trilinolein has been reported to be trans-4,5-epoxy2(E)-decenal (Lin et al., 2001), which was isolated from the oil. This compound has been reported reactive with nucleophiles on proteins, leading to loss of cell function and viability (Zamora and Hidalgo, 1994). Therefore, it could be suggested that the presence of 2- $(E)$-decenal in the essential oil extracted by SME has contributed to the increase in brine shrimp mortality over the treatment containing the HDE-extracted oil in addition to increased oil concentrations. Trans-4,5-epoxy-2(E)-decenal has also been found to be a useful tool in elucidating the effects of peroxidative damage in experimental models (Zamora and Hidalgo, 1994). The derivatives of 2-pyrrolecarbonitrile are important constituents in the synthesis of porphobilinogen and the main building block used in the biosynthesis of pigments in plant
(Santos and Ribeiro da Silva, 2012). Another derivative such as tetrapyrrolic compounds has been applied in photodynamic therapy for the treatment of cancer. Potent activity of synthesized 2-pyrrolecarbonitrile has been demonstrated on the progesterone receptor antagonist, which can be a potential contraceptive agent (Santos and Ribeiro da Silva, 2012). The volatile oils of Moringa oleifera seeds obtained by HDE and SME methods contain aromatic hydrocarbons, phenols, ketones, organic acids, and different terpenes, which may have impacted inhibitory effects on the shrimp larvae at different concentrations over time. The varied occurrences of these compounds in the oil samples may indicate that their inhibitory effects on the shrimp larvae were not the direct effect of a compound or single group, but rather that the compounds possibly acted in synergy to bring about a toxic effect especially at higher doses. The non-toxicity effect of both the SME and HDE essential oils at $1000 \mu \mathrm{g} / \mathrm{ml}$ is in agreement with Meyer's index for non-toxic oil (Meyer et al., 1982; Gupta et al., 1996). This may be an advantage for the utilization of the essential oil of Moringa oleifera seeds over some antioxidant and antimicrobial chemical substances commonly used as therapeutic agents, preservatives or as carriers of other useful additives in cosmetics and processed foods.

\section{Conclusions}

The renewed interest of the pharmaceutical industries and food processors in essential oils as possible natural substances to replace synthetic drugs and preservatives has redirected the focus of many researchers. This study revealed the chemical composition of the volatile oils of Moringa oleifera seeds extracted by different methods. The chemical compositions of the volatile oils of the HDE and SME varied considerably. Thus, SME-extracted volatile oil possessed a greater number of chemical compounds, some of which were not detected in the HDE oil. This observation is in agreement with the report of Okoh et al. (2010). The volatile oils were toxicologically screened using the brine shrimp egg hatchability test and larva mortality at different concentrations and durations of incubation. It was revealed that the shrimp eggs and larvae were more sensitive to the SME oil 
than to the HDE oil, and were both significantly different $(P<0.05)$ when compared with the natural sea water control samples, although the oil-treated samples were found to be significantly lower $(P<0.05)$ compared with chloramphenicol-treated sample (positive control). The predominant activities of the SME volatile oil over the HDE volatile oil may partly be due to the greater number of oxygenated compounds present in the SME volatile oil, many of which have been proved to be strongly active antimicrobial agents (Nyaitondi, 2007; Sandri et al., 2007). The SME and HDE volatile oils of Moringa oleifera seeds exhibited low brine shrimp larva toxicity and possessed $\mathrm{LC}_{50}$ values of 2908.23 and $3473.63 \mu \mathrm{g} / \mathrm{ml}$, respectively. These values were greater than $1000 \mu \mathrm{g} / \mathrm{ml} \mathrm{recom}$ mended as an index for non-toxic oil (Meyer et al., 1982). As such, the oil may be explored for the development of useful plant-based pharmaceuticals, food preservatives and antioxidant agents or as carriers of other additives such as flavor in processed foods and fragrance in cosmetic production.

\section{Acknowledgements}

We greatly acknowledged the University of Fort Hare, Alice, South Africa for granting one of the authors the opportunity to serve as a research visitor in the institution and her financial support through Govan Mbeki Research and Development Centre in the publication of these research findings.

\section{Compliance with ethics guidelines}

Rowland Monday Ojo KAYODE and Anthony Jide AFOLAYAN declare that they have no conflict of interest.

This article does not contain any studies with human or animal subjects performed by any of the authors.

\section{References}

Adams, R.P., 1995. Identification of Essential Oil Components by Gas Chromatography/Mass Spectroscopy. Allured Publishing, Carol Stream, IL.

Anneken, D.J., Sabine, B., Christoph, R., et al., 2006. Fatty acids. In: Ullmann's Encyclopedia of Industrial Chemistry, 7th Ed. Wiley-VCH, Weinheim.

Brenes, A., Roura, E., 2010. Essential oils in poultry nutrition: main effects and modes of action. Anim. Feed Sci. Technol., 158(1-2):1-14. [doi:10.1016/j.anifeedsci.2010. 03.007]

Burt, S., 2004. Essential oils: their antibacterial properties and potential applications in foods-a review. Int. J. Food Microbiol., 94(3):223-253. [doi:10.1016/j.ijfoodmicro. 2004.03.022]

Caballero, B., Trugo, L.C., Finglas, P.M., 2003. Encyclopedia of Food Sciences and Nutrition. Academic Press,
Amsterdam.

Carballo, J.L., Hernández-Inda, Z.L., Pérez, P., et al., 2002. A comparison between two brine shrimp assays to detect in vitro cytotoxicity in marine natural products. $B M C$ Biotechnol., 2(1):17. [doi:10.1186/1472-6750-2-17]

Chuang, P., Lee, C.W., Chou, J.Y., et al., 2007. Anti-fungal activity of crude extracts and essential oil of Moringa oleifera Lam. Bioresour. Technol., 98(1):232-236. [doi:10.1016/j.biortech.2005.11.003]

Demuner, A.J., Barbosa, L.C.A., Magalhaes, C.G., et al., 2011. Seasonal variation in the chemical composition and antimicrobial activity of volatile oils of three species of Leptospermum (Myrtaceae) grown in Brazil. Molecules, 16(12):1181-1191. [doi:10.3390/molecules16021181]

Dillard, C.J., German, J.B., 2000. Phytochemicals: nutraceuticals and human health. J. Sci. Food Agric., 80(12): 1744-1756. [doi:10.1002/1097-0010(20000915)80:12< 1744::AID-JSFA725>3.0.CO;2-W]

Guevara, A.P., Vargas, C., Sakurai, H., et al., 1999. An antitumor promoter from Moringa oleifera Lam. Mutat. Res., 440(2):181-188. [doi:10.1016/S1383-5718(99)00025-X]

Gupta, M.P., Monge, A., Karikas, G.A., et al., 1996. Screening of Panamanian medicinal plants for brine shrimp toxicity, crown gall tumor inhibition, cytotoxicity and DNA intercalation. Pharm. Biol., 34(1):19-27. [doi:10.1076/ phbi.34.1.19.13180]

Hyldgaard, M., Mygind, T., Meyer, R.L., 2012. Essential oils in food preservation: mode of action, synergies, and interactions with food matrix components. Front. Microbiol., 3:12. [doi:10.3389/fmicb.2012.00012]

IUPAC (International Units of Pure and Applied Chemistry), 1997. Compendium of Chemical Terminology, 2nd Ed. Compiled by A.D. McNaught and A. Wilkinson, Blackwell Scientific Publications, Oxford, UK.

Khajeh, M., Yamini, Y., Sefidkon, F., et al., 2004. Comparison of essential oil of Carom copticum obtained by supercritical carbondioxide extraction and hydrodistillation methods. Food Chem., 86(4):587-591. [doi:10.1016/j. foodchem.2003.09.041]

Kováts, E., 1958. Gas chromatographische charakterisierung organischer verbindungen. Teil 1: retentionsindices aliphatischer halogenide, alkohole, aldehyde und ketone. Helv. Chim. Acta, 41(7):1915-1932 (in German). [doi:10. 1002/hlca.19580410703]

Lewis, G.E., 1995. Testing the toxicity of extracts of southern African plants using brine shrimp (Artemia salina). South Afr. J. Sci., 91(8):382.

Lin, J., Fay, L.B., Welti, D.H., 2001. Quantification of key odorants formed by autoxidation of arachidonic acid using isotope dilution assay. Lipids, 36(7):749-756. [doi:10.1007/s11745-001-0781-x]

Lucchesi, M.E., Chemat, F., Smadja, J., 2004. Solvent-free microwave extraction of essential oil from aromatic herbs: comparison with conventional hydro-distillation. $J$. Chromatogr. A, 1043(2):323-327. [doi:10.1016/j.chroma. 2004.05.083]

Lyman, W.J., Reehl, W.F., Rosenblatt, D.H., et al., 1990. 
Handbook of Chemical Property Estimation Methods. American Chemical Society, Washington, DC, p.7-12.

Meyer, B.N., Ferrigni, N.R., Putnam, J.E., et al., 1982. Brine shrimp: a convenient general bioassay for active plant constituents. Planta Med., 45(5):31-34. [doi:10.1055/ s-2007-971236]

Meylan, W.M., Howard, P.H., 1993. Computer estimation of the Atmospheric gas-phase reaction rate of organic compounds with hydroxyl radicals and ozone. Chemosphere, 26(12):2293-2299. [doi:10.1016/0045-6535(93) 90355-9]

New Jersey Department of Health and Senior Services, 1999. Hazadous Substance Facts Sheet. Trenton, NJ, USA, p.1-6.

Nkya, J.W., Erasto, P., Chacha, M., 2014. Larvicidal against mosquito vectors and brine shrimp activities of extracts from the flowers of Moringa Oleifera Lam. Amer. J. Res. Comm., 2(8):15-29.

Nyaitondi, O.D., 2007. Anti-bacterial Properties and GC-MS Analysis of Extracts and Essential Oils of Selected Plant Products. MSc Thesis, School of Pure and Applied Sciences of Kenyatta University, Kenya.

Okoh, O.O., Afolayan, A.J., 2011. The effects of hydrodistillation and solvent free microwave extraction methods on the chemical composition and toxicity of essential oils from the leaves of Mentha longifolia L. subsp. capensis. Afr. J. Pharm. Pharmacol., 5(22):2478.

Okoh, O.O., Sadimenko, A.P., Afolayan, A.J., 2010. Comparative evaluation of the antibacterial activities of the essential oils of Rosmarinus officinalis L. obtained by hydrodistillation and solvent free microwave extraction methods. Food Chem., 120(1):308-312. [doi:10.1016/ j.foodchem.2009.09.084]

Okuniewski, A., Becker, B., 2011. Ammonium $O, O^{\prime}$-diethyl dithiophosphate. Acta Cryst., 67(7):1749-1750.

Otang, W.M., Grierson, D.S., Ndip, R.N., 2013. Assessment of potential toxicity of three South African medicinal plants using the brine shrimp (Artemia salina) assay. Afr. J. Pharm. Pharmacol., 7(20):1272-1279. [doi:10.5897/ajpp12. 264]

Pare, J.R.P., Belanger, J.M.R., 1997. Instrumental Methods in Food Analysis. Elsevier, Amsterdam, the Netherlands.

Pereira, C.G., Meireles, M.A.A., 2010. Supercritical fluid extraction of bioactive compounds: fundamentals, applications and economic perspectives. Food Bioprocess Technol., 3(3):340-372. [doi:10.1007/s11947-009-0263-2]

Pour, B.M., Sasidharan, S., 2011. In vivo toxicity study of Lantana camara. Asian Pac. J. Trop. Biomed., 1(3): 230-232. [doi:10.1016/S2221-1691(11)60033-6]

Ramachandran, C., Peter, K.V., Gopalakrishnan, P.K., 1980. Drumstick (Moringa oleifera): a multipurpose Indian vegetable. Econ. Bot., 34(3):276-283. [doi:10.1007/BF 02858648]

Sánchez, E., García, S., Heredia, N., 2010. Extracts of edible and medicinal plants damage membranes of Vibrio cholerae. Appl. Environ. Microbiol., 76(20):6888-6894. [doi:10.1128/AEM.03052-09]
Sandri, I.G., Zacaria, J., Fracaro, F., et al., 2007. Antimicrobial activity of the essential oils of Brazilian species of the genus Cunila against foodborne pathogens and spoiling bacteria. J. Ethnopharmacol., 103(3):823-828. [doi:10. 1016/j.foodchem.2006.09.032]

Santos, A.F.L.O.M., Ribeiro da Silva, M.A.V., 2012. Molecular energetics of pyrrolecarbonitriles and derivatives: a combined calorimetric and computational study. J. Chem. Thermodyn., 48:194-200. [doi:10.1016/j.jct.2011.12.019]

Siddhuraju, P., Becker, K., 2003. Antioxidant properties of various solvent extracts of total phenolic constituents from three different agro-climatic origins of drumstick tree (Moringa oleifera Lam.). J. Agric. Food Chem., 51(8):2144-2155. [doi:10.1021/jf020444+]

Taira, H., Nakagahra, M., Nagamine, T., 1988. Fatty acid composition of Indica, Sinica, Japonica, and Japonica groups of nonglutinous brown rice. J. Agric. Food Chem., 36(1):45-47. [doi:10.1021/jf00079a 011]

Verschueren, K., 1996. Handbook of Environmental Data on Organic Chemicals, 3rd Ed. van Nostrand Reinhold Co., New York, NY, p.1443.

Zamora, R., Hidalgo, F.J., 1994. Modification of lysine amino groups by the lipid peroxidation product 4,5(E)-Epoxy2(E)-heptenal. Lipids, 29(4):243-249. [doi:10.1007/BF 02536328]

\section{中文概要}

题 目: 辣木籽精油的细胞毒性及其提取方法对化学成分 的影响

目 的: 研究水蒸汽蒸馏法 (HDE) 和无溶剂微波萃取法 (SME) 对辣木籽精油化学组成的影响, 并评估 精油的细胞毒性。

创新点: 比较了不同的提取精油方法对精油的化学成分及 其细胞毒性的影响。

方 法: 分别采用 HDE 和 SME 两种方法提取辣木䊏精油, 然后使用气相色谱-质谱法分析其化学成分。通过 比较在不同浓度和瞬化时间下盐水虾卵的孵化 率和幼虾的死亡率来检测精油的细胞毒性。

结 论: HDE 和 SME 两种方法提取的辣木䊏精油分别含 有 16 和 26 种化学成分, 各自占总可识别成分的 97.515\%和 97.816\%。因此, SME 提取法含有更 多的成分。盐水虾卵分别在含有两种精油、海水 和氯霉素的样品中孵化 $24 \mathrm{~h}$ 后, 睬化率分别为 $60.0 \%$ (HDE）、 $56.7 \%$ (SME）、63.3\%（海水） 和 $15.0 \%$ (氯霉素)，精油中的睬化率远高于含 有氯霉素的样品的睬化率 $(P<0.05)$ 。同时, SME 和 HDE 精油对幼虾的半致死量分别为 2908.23 和 $3473.63 \mu \mathrm{g} / \mathrm{ml}$ （大于 $1000 \mu \mathrm{g} / \mathrm{ml}$ 被认为无毒）。 因此, 两种方法提取的精油可广泛适用于药物、 食品防腐剂、抗氧化剂和香料等添加剂。

关键词: 辣木䊏; 提取方法; 精油; 细胞毒性 